\title{
D-Limonen ve Nanoselüloz İçeren Aktif Kitosan/Polikaprolakton İki Katmanlı Filmler
}

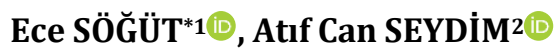 \\ 1,2 Süleyman Demirel Üniversitesi, Mühendislik Fakültesi, Gıda Mühendisliği Bölümü, 32260, Isparta, Türkiye
}

(Alınış / Received: 29.10.2020, Kabul / Accepted: 15.11.2020, Online Yayınlanma / Published Online: 20.12.2020)

\author{
Anahtar Kelimeler \\ Kitosan, \\ Polikaprolakton, \\ D-limonen, \\ Nanoselüloz, \\ Aktif iki katmanlı film
}

Özet: Bu çalışmanın amacı, polikaprolaktonun (PCL), kitosan (CH) film üzerine kaplandığında, PCL ikinci katmanının filmlerin fiziksel, antioksidan ve antimikrobiyal özellikleri üzerine etkisini değerlendirmektir. D-limonen $(\% 5$, $\mathrm{w} / \mathrm{w})$ ve nanoselüloz $(\mathrm{N})(\% 2, \mathrm{w} / \mathrm{w}), \mathrm{CH}$ film çözeltilerine ilave edilmiş ve daha sonra gıda ambalajlama uygulamaları için PCL ile kaplanarak aktif çift katmanlı filmler elde edilmiștir. Film örnekleri optik analiz, geçirgenlik testleri, antioksidan ve antimikrobiyal aktivite testleri ile karakterize edilmiştir. CH üzerindeki PCL katmanı filmlerin su buharı geçirgenliğini geliştirirken, çift katmanlı filmler daha opak olarak gözlenmiştir. CH filmlere D-limonen ilave edilmesi, film örneklerinin su buharı ve ışık geçirgenlik değerlerinde azalışa neden olmuştur ancak bu azalış iki katmanlı filmlerde gözlenen azalış kadar yüksek değildir. D-limonen içeren film örnekleri hem antioksidan kapasite hem de seçilen bakterilere karşı antimikrobiyal aktivite göstermiştir.

\section{Active Chitosan/Polycaprolactone Bilayer Films Including D-Limonene and Nanocellulose}

\section{Keywords \\ Chitosan, \\ Polycaprolactone, \\ D-limonene, \\ Nanocellulose, \\ Active bilayer film}

\begin{abstract}
The objective of this study was to evaluate the effect of polycaprolactone (PCL) on the physical and active properties of films when coated on chitosan (CH) film. D-limonene $(5 \%, w / w)$ and nanocellulose $(\mathrm{N})(2 \%, \mathrm{w} / \mathrm{w})$ were added to $\mathrm{CH}$ film solutions, and then coated with PCL to develop active bilayer-films for food packaging applications. Film samples were characterized by permeability tests, optical analysis, antioxidant and antimicrobial activity tests. PCL layer on $\mathrm{CH}$ improved the permeability while bilayer films were observed as more opaque. The addition of D-limonene into $\mathrm{CH}$ films caused a decrease in the water vapor permeability and light transmittance values of the film samples, however, this decrease was not high those observed in bilayer films. Film samples including Dlimonene showed both antioxidant capacity and antimicrobial activity against selected bacteria.
\end{abstract}

\section{Giriş}

Son zamanlarda, yenilenebilir kaynaklardan elde edilen biyo-bazlı polimerlerin, petrol bazlı plastiklere alternatif olarak kullanılma potansiyeli üzerine yapılan çalışmalar artış göstermektedir [1,2]. Özellikle doğal antimikrobiyal/antioksidan bileșenlerle zenginleștirilmiş polisakkaritler, proteinler ve lipitler gibi aktif biyo-bazlı polimerler, son yıllarda gıda ambalaj sektöründe büyük ilgi görmektedir [3]. Yenilenebilir kaynaklardan elde edilen biyo-bazlı polimerler arasında kitosanın $(\mathrm{CH})$ iyi film oluşturma özellikleri, stabilite, esneklik, biyouyumluluk, biyobozunurluk ve ticari kullanılabilirlik sergilediği yapılan çalışmalarda gösterilmiştir $[4,5]$. $\mathrm{CH}$, yengeç ve karides gibi kabukluların dış iskeletinin ana bileșeni olan kitinin deasetilasyonu sonucu bir deniz ürününün yan ürünü olarak ticari şekilde elde edilebilen lineer bir polisakkarittir. Katyonik karakteri ile bağlantılı olarak, çeşitli çalışmalar CH'nin mayalar, küfler, Gram pozitif ve Gram negatif bakterilere karşı geniş inhibisyon spektrumu gösterdiğini belirtmiştir [6-8]. Ancak $\mathrm{CH}$ filmlerin bariyer, mekanik ve isıl stabilite gibi özelliklerinin petrol bazlı plastiklerle karşılaştırıldığında zayıf olmasından dolayı kullanımı sınırlıdır [9]. CH bazlı filmlerin özelliklerini geliştirmek için diğer biyo-bazlı polimerlerle harmanlama [10], nanodolgu maddesi ilave etme [11], kimyasal ve enzimatik çapraz bağlama gibi çeşitli yöntemler önerilmiştir [12]. Bu alanda, nanokompozitler özellikle ilgi çekicidir, çünkü nano boyutlu dolgu maddelerinin yüksek 
matris/dolgu ara yüz alanı nedeniyle biyo-bazlı polimerlerin bariyer ve mekanik özelliklerini geliştirmede etkili olduğu kanıtlanmıştır [13]. Nanodolgu malzemeleri arasında, nanoselüloz (N) partikülleri, selüloz ve $\mathrm{CH}$ arasındaki benzerlik nedeniyle CH'nin özelliklerini geliştirme potansiyeline sahip malzemeler arasında gösterilmektedir $\quad[14,15]$. Nanokompozitler, antioksidanlar ve antimikrobiyaller gibi bazı aktif bileşiklerin taşıyıcıları olarak da kullanılmaktadır $[16,17]$. CH filmlerin bariyer ve mekanik özellikleri, kullanılan polimerlerin avantajlarını birleştirmek ve dezavantajlarını en aza indirmek için diğer polimerlerle lamine edilerek de geliștirilebilir $[18,19]$. Laminasyon, farklı filmlerin özelliklerini tek bir tabakada birleştirerek polimerik filmlerin performansını artırmanın bir diğer yoludur [20]. Genel olarak, diş katmanlar nem direnci ve mekanik stabilite sağlarken, iç katman bir gaz bariyeri görevi görür [12] veya aktif bileşen taşıyıcısı olarak kullanılır [21]. CH bazlı iki katmanlı filmlerin bariyer ve mekanik özelliklerinin CH tek katmanl filmler ile karşılaştırıldığında geliştirildiğini gösteren çalışmalar mevcuttur [10,20,22]. Polikaprolakton (PCL), CH filmlerin özelliklerini geliștirmek için üst katman olarak kullanılabilecek biyobozunur özellikte sentetik polimerdir. PCL, kaprolakton monomerinin halka açılımı polimerizasyonu yoluyla ham petrolden kimyasal sentezle üretilen termoplastik alifatik bir polyesterdir [23]. Yapılan çalışmalarda, CH ve PCL bazlı harman ve/veya katmanlı filmlerin, mekanik dayanım ve bariyer özelliklerinin iyileştirildiği belirtilmiştir [24,25].

Gıda kalitesi ve güvenliğiyle ilgili artan endişeler nedeniyle, gıda raf ömrünü uzatmak için özellikle antioksidan ve antimikrobiyal ambalaj uygulamaları gibi aktif ambalaj geliştirmeye olan ilgi artmıştır $[26,27]$. Bu alanda en çok kullanılan aktif bileşenler arasında güçlü biyolojik aktiviteye sahip uçucu yağlar bulunmaktadır. Turunçgil endüstrisinin en önemli kalıntılarından olan ve portakal kabuğu yağının yaklaşık \%90'ını oluşturan D-limonen (DL), aktif özelliklere sahip bir siklik terpendir [28]. DL'nin antimikrobiyal aktivitesinin Staphylococcus aureus, Listeria monocytogenes, Salmonella enterica gibi farklı patojenlere karşı denendiği çalışmalar mevcuttur $[29,30]$. Ancak DL'nin çok çabuk oksidasyona uğraması ve kolaylıkla ambalajlanmış gıdaya salınarak gıdayı kontamine etmesi gibi bazı problemler meydana gelmektedir [31]. Bu problemlerin üstesinden gelebilmek için DL'nin ortama salımını yavaşlatacak nanoselüloz gibi bir taşıyıcı ile biyo-bazlı polimerik yapıya ilave edilmesi ve aroma bileșeni olarak ambalaj malzemesi boyunca difüzyonunu kontrol altına almak için katmanlı ambalaj malzemelerinde kullanımı gerçekleştirilebilir. Bu nedenle bu çalışmanın amacı, CH'nin işlevselliğini ve fiziko-mekanik özelliklerini geliştirme potansiyeline sahip, DL ve $\mathrm{N}$ ile birleştirilmiş $\mathrm{CH}$ ve PCL bazlı aktif çift katmanlı filmler elde etmektir.

\section{Materyal ve Metot}

\subsection{Materyal}

Kitosan (CH), (ChitoClear® CG1600, molekül ağırlığı $>320 \mathrm{kDa}, 1600 \mathrm{cP},>75 \%$ deasetillenmiş) Primex EHF'den (ChitoClear®, Siglufjordur, İzlanda) ve polikaprolakton (PCL, CAPA 6800) Perstorp Holding AB (İsveç)'den temin edilmiştir. Nanoselüloz (N) (\%80 kristallenme derecesinde, kristal çapı 9-14 nm ve kristal uzunluğu maksimum $100 \mathrm{~nm}$ ), \%8 (w/w) süspansiyon halinde Blue Goose Biorefineries Inc. (BGB ULTRA ${ }^{\mathrm{TM}}$, Kanada) firmasından alınmıștır. Dlimonen (DL), Kimbiotek A.Ş. (Ankara, Türkiye)'den temin edilmiştir. Tüm kimyasallar analitik saflıkta ve Nutrient broth ile Nutrient agar ise mikrobiyolojik saflıkta olup sırasıyla Sigma-Aldrich (St. Louis, Missouri, ABD) ve Merck (Darmstadt, Almanya)'den temin edilmiştir.

\subsection{Film örneklerinin hazırlanması}

CH film örnekleri dökme yöntemi kullanılarak üretilmiștir. $\mathrm{CH}(\% 1,5)(\mathrm{w} / \mathrm{w}), \% 1$ asetik asit çözeltisi (w/w) kullanılarak $25^{\circ} \mathrm{C}$ 'de çözündürülmüş ve daha sonra plastifiyan olarak \%0,25 (w/w, film çözeltisi bazında) oranında gliserol ilave edilmiştir. Elde edilen film çözeltisine $\% 2$ oranında $\mathrm{N}$ ve $\% 5$ oranında DL eklenerek homojenizatör (DAIHAN HG-15A, Korea) yardımıyla homojen (10000 rpm/5 dak) hale getirilmiştir. Vakum altında film çözeltisindeki gaz kabarcıkları uzaklaşturıldıktan sonra $50 \mathrm{~g}$ film çözeltisi teflon kaplı petrilere $(\varnothing=150 \mathrm{~mm})$ dökülmüș ve oda sıcaklığında 48 sa boyunca kurutulmuştur. Kuruyan filmler petrilerden alındıktan sonra ikinci katman ile kaplama işlemine geçilmiştir. Kaplama film çözeltisi, PCL'in (\%5, w/w) kloroformda çözündürülmesiyle elde edilmiştir. Elde edilen PCL film çözeltisi kuruyan $\mathrm{CH}$ film örneklerinin üzerine dökülmüș ve kalınlığı $200 \mu \mathrm{m}$, (spiral bar coater, Elcometer 4360/30, Manchester, İngiltere) olan kaplama çubuğu ile homojen şekilde kaplanmış ve oda sıcaklığında kurutulmuştur. İki katmanlı filmlerin kalınlıkları CH film üzerine dökülen PCL film çözeltisi miktarı ayarlanarak kontrol altında tutulmuştur. Tüm film örnekleri analiz edilmeden önce $25^{\circ} \mathrm{C}$ ve $\% 53$ bağll nem (RH) altında 1 hafta boyunca koşullandırılmıştır. Koşullandırılan örneklerin kalınlık değerleri dijital mikrometre (Digimatic Micrometer Quantu-Mike IP65, Mitutoyo, Japonya) yardımıyla en az 6 farklı bölgeden rastgele ölçüm alınarak belirlenmiştir. Film örneklerine ait kodlamalar Tablo 1'de verildiği gibidir. 
Tablo 1. Film örneklerine ait kodlamalar

\begin{tabular}{|c|c|}
\hline Film kodu & Açıklama \\
\hline $\mathrm{CH}$ & CH film (negatif kontrol) \\
\hline $\mathrm{CHN}$ & $\begin{array}{l}\% 2 \text { oranında } \mathrm{N} \text { içeren } \mathrm{CH} \text { film (pozitif } \\
\text { kontrol) }\end{array}$ \\
\hline CHN-DL & $\begin{array}{l}\% 2 \text { oranında } \mathrm{N} \text { ve } \% 5 \text { oranında DL içeren } \\
\text { CH film }\end{array}$ \\
\hline CHN/PCL & $\% 2$ oranında $\mathrm{N}$ içeren iki katmanlı $\mathrm{CH}$ film \\
\hline $\begin{array}{l}\text { CHN- } \\
\text { DL/PCL }\end{array}$ & $\begin{array}{l}\% 2 \text { oranında } \mathrm{N} \text { ve } \% 5 \text { oranında DL içeren } \\
\text { iki katmanlı } \mathrm{CH} \text { film }\end{array}$ \\
\hline $\begin{array}{l}\text { 2.3. Fil } \\
\text { belirlenm }\end{array}$ & erin su buharı geçirgenliğini \\
\hline
\end{tabular}

Film örneklerinin su buharı geçirgenlik değerleri (WVP), ASTM E96-95 [32] standart yöntemi ile belirlenmiştir. Geçirgenlik kapları kullanılarak, elde edilen filmlerin $\mathrm{CH}$ katmanı \%100 RH'ya ve üst katman \%53 RH'ya maruz birakılmıştır. Filmlerin geçirgenlik değerleri, geçirgenlik kaplarının $25^{\circ} \mathrm{C}$ 'de 48 sa boyunca her 90 dak periyodik olarak tartılması ile belirlenmiştir. Her bir örneğin geçirgenlik hızı lineer regresyon kullanılarak hesaplanmıştır.

\subsection{Filmlerin optik özelliklerinin belirlenmesi}

Filmlerin opaklık değerleri Friesen ve ark. [33] tarafindan uygulanan yöntem kullanılarak UV-Vis spektrofotometre (Shimadzu, UV-1601, Tokyo, Japonya) ile belirlenmiştir. $1 \mathrm{x} 4 \mathrm{~cm}$ boyutlarında kesilen film örneklerinin opaklık değerleri, 400-800 $\mathrm{nm}$ dalga boyları arasinda elde edilen absorpsiyon spektrum alanlarının filmlerin kalınlıklarına bölünmesiyle hesaplanmıştır (AU nm/mm). Filmlerin ışık geçirgenliği değerleri $(\mathrm{T}, \%)$, UV-visspektrofotometre (Shimadzu, UV-1601, Tokyo, Japonya) ile $450 \mathrm{~nm}$ 'deki geçirgenlik yüzdesi hesaplanarak ölçülmüştür. Film örneklerinin renk değerleri ise, beyaz standart kalibrasyon plakası ( $Y=92,7 ; x=0,3160 ; y=0,3321)$ kullanılarak Minolta renk ölçüm cihazı (CR-400, Konica Minolta, Inc., Japan) ile belirlenmiştir. Sonuçlar, CIE $L^{*}$ (parlaklık), $a^{*} \quad$ (kırmızı-yeşil) ve $b^{*}$ (sarı-mavi) şeklinde verilmiștir.

\subsection{Filmlerin antioksidan aktivitelerinin belirlenmesi}

Film örneklerinin potansiyel antioksidan aktivitesi, kararlı radikal 2,2-difenil-1-pikrilhidrazil (DPPH) kullanılarak radikal süpürme aktivitesi şeklinde belirlenmiștir [34]. Film örnekleri bir hafta boyunca çözücü sistem olarak etanol ve su karışımına (50/50, v/v) maruz bırakılmıştır. Siklik yapıdaki terpenlerden olan DL, suya göre etanolde daha fazla çözünür ve etanol konsantrasyonundaki artış, DL'nin çözünürlüğünü artıracaktır. Ön çalışmalarımızda, etanol konsantrasyonundaki artışın film örneklerinin etanolde hidrate olmasını sınırlandırdığı ve polimer ağının zayıflatıcı etkisi nedeniyle, film matrisinden DL difüzyonunun zorlaștığı görülmüştür. Bu nedenle, bu çalışmada, film örneklerinin potansiyel en yüksek antioksidan aktivitesini bulmak için, maksimum DL miktarını elde etmede çözücü olarak \%50 etanol konsantrasyonu seçilmiştir. Alınan örnekler 0,1 mM konsantrasyondaki DPPH çözeltisi ile muamele edildikten sonra 40 dak boyunca oda sicaklığında ve karanlıkta inkübe edilmiş, ardından spektrofotometre (Shimadzu, UV-1601, Tokyo, Japonya) yardımıyla örneklerin $517 \mathrm{~nm}$ dalga boyundaki absorbans değerleri okunmuştur. Örneklerin antioksidan aktiviteleri, 0,1 mM DPPH çözeltisinin indirgenme yüzdesi olarak ifade edilmiștir.

\subsection{Filmlerin antimikrobiyal aktivitelerinin belirlenmesi}

Film örneklerinin antimikrobiyal etkileri, zon inhibisyon yöntemi kullanılarak Escherichia coli (ATCC 26922), Listeria monocytogenes (ATCC 19115), Staphylococcus aureus (ATCC 25923) ve Pseudomonas aeruginosa'ya (ATCC 27853) karşı test edilmiştir. Bu mikroorganizmalar, gida bozulmasından sorumlu olan ana bakterilerden bazılarıdır. Nutrient broth sıvı besiyeri kullanılarak $37^{\circ} \mathrm{C}$ 'de 18 sa boyunca inkübe edilerek geliştirilen saf kültür örnekleri, 6-8 log koloni oluşturan birim (kob)/mL konsantrasyonda olacak şekilde Nutrient agar besiyeri bulunan petrilere aktarılmıştır. UV-C ışık altında 15 dak boyunca steril edilen film örnekleri $(\varnothing=15 \mathrm{~mm})$ bakteri suşları ile aşılanmış Petri kaplarına yerleştirilmiştir. Petriler 24 sa $37^{\circ}$ C'de inkübe edilmiş ve petrilerdeki mikrobiyal gelişim, film örneklerinin etrafındaki berrak zon $(\mathrm{mm})$ açısından incelenmiştir.

\section{7. İstatistiksel analiz}

İstatistiksel analiz SPSS 17 (SPSS Inc. Chicago, IL, ABD) paket programı kullanılarak gerçekleştirilmiştir. Her deney, her film için en az üç gözlemle üç kez tekrarlanmıștır. Örnekler arasındaki önemli farklılıklar \%95 güven aralığında Tukey çoklu karşılaştırma testi kullanılarak belirlenmiştir.

\section{Bulgular ve Tartışma}

\subsection{Film örneklerin su buharı geçirgenlik değerleri}

Ambalaj malzemelerinin su buharı geçirgenlik özellikleri gıdanın raf ömrü ile ilişkili olan organoleptik özelliklerinin korunmasında anahtar parametrelerden biridir ve nem transferinin etkin bir şekilde kontrol edilebilmesi için belirlenmesi gerekmektedir. Gldadan ambalaj atmosferine veya dışarıdan gıdaya nem transferini azaltmak veya ortadan kaldırmak için, ambalaj malzemesinin WVP değerlerinin mümkün olduğunca az olması beklenir [35]. Film örneklerine ait su buharı geçirgenlik değerleri Şekil 1'de gösterilmiştir.

$\mathrm{Bu}$ çalışmada en düşük WVP değerleri iki katmanlı filmlerde gözlemlenirken $(\mathrm{p}<0,05)$, DL ve $N$ ilavesinin 
filmlerin WVP değerlerinde azalışa neden olsa da istatistiksel olarak önemli ölçüde değişikliğe neden olmadığı belirlenmiştir. Yapılan bazı çalışmalar hidrofilik filmler için, artan kalınlığın filmin iç yüzeyindeki kısmi su buharı basıncını arttırarak kütle transferi için sürükleyici kuvvet oluşturması nedeniyle, film kalınlıkları ile WVP değerleri arasında pozitif korelasyon olduğunu göstermiştir [36]. Ancak elde edilen sonuçlara göre CHN ve CHN-DL filmler, $\mathrm{CH}$ filmine göre daha kalın olmasına rağmen daha düșük WVP değerleri göstermiștir. Bu durum, $\mathrm{CH}$ film yapısına ilave edilen bileşiklerin polimer matrisi ile etkileşim göstererek, su ile etkileşim verebilecek hidrofilik grupların sayısını azaltması ve sonuç olarak su buharı geçirgenliğini düşürmesi ile açıklanabilir [13]. DL'nin nispeten daha hidrofobik yapıda olması, CH filmlerin daha yüksek bir nem bariyeri ve su direnci göstermesine neden olabilir. Bu nedenle, DL içeren filmler, daha düşük WVP değerleri göstermiştir $(p>0,05)$ ve bu durum DL'nin eklenmesinin, $\mathrm{CH}$ matrisindeki su transferi için suyun transfer uzunluğunda bir artışa neden olmasından da kaynaklanıyor olabilir. Bunun yanı sıra, iki katmanlı filmlerde PCL'in kullanımı ile $\mathrm{CH}$ filmlerin WVP değerleri yaklaşık \%80 oranında azaltılmıştır. Bu durum PCL'in hidrofobik yapısı ve bu nedenle su buharı geçişini yavaşlatması ile açıklanabilir. Elde edilen sonuçlar Söğüt ve Seydim [11] ve Salgado ve ark. [37] tarafından $\mathrm{CH} /$ sikloolefin kopolimer ve soya proteini izolatı/polihidroksi bütirat bazlı iki katmanlı filmler için elde edilen sonuçlarla benzerlik göstermektedir.



Şekil 1. Filmlerin su buharı geçirgenlik değerleri a-b Farklı harfler, örnekler arasında önemli farklılıkları gösterir $(\mathrm{p}<0,05)$

\subsection{Film örneklerin optik özellikleri}

Film örneklerinin kalınlık, ışık geçirgenliği (T, \%), opaklık ve renk değerleri sırasıyla Tablo 2 ve Tablo 3'te verildiği gösterilmiştir.
Tablo 2. Film örneklerinin kalınlık, ıșık geçirgenliği ve opaklık değerleri

\begin{tabular}{llll}
\hline Film & $\begin{array}{l}\text { Kalınlık } \\
(\boldsymbol{\mu m})\end{array}$ & T (\%) & $\begin{array}{l}\text { Opaklık } \\
\mathbf{( A U} \\
\mathbf{n m} / \boldsymbol{\mu m})\end{array}$ \\
\hline CH & $36,0 \pm 1,4^{\mathrm{b}}$ & $69,1 \pm 5,7^{\mathrm{ab}}$ & $0,8 \pm 0,1^{\mathrm{b}}$ \\
\hline CHN & $36,1 \pm 4,2^{\mathrm{b}}$ & $70,7 \pm 0,4^{\mathrm{a}}$ & $1,2 \pm 0,1^{\mathrm{b}}$ \\
\hline CHN-DL & $39,5 \pm 0,7^{\mathrm{a}}$ & $49,3 \pm 4,6^{\mathrm{c}}$ & $3,8 \pm 1,6^{\mathrm{a}}$ \\
\hline CHN/PCL & $48,0 \pm 1,4^{\mathrm{a}}$ & $55,7 \pm 2,5^{\mathrm{bc}}$ & $2,2 \pm 0,2^{\mathrm{a}}$ \\
\hline CHN-DL/PCL & $49,8 \pm 2,8^{\mathrm{a}}$ & $34,2 \pm 2,7^{\mathrm{d}}$ & $3,9 \pm 1,0^{\mathrm{a}}$ \\
\hline
\end{tabular}

a-c Aynı sütundaki farklı harfler, örnekler arasında önemli farklılıkları gösterir $(\mathrm{p}<0,05)$

$\mathrm{CH}, \mathrm{CHN}$ ve CHN-DL film örnekleri kalınlıklarını kontrol edebilmek amacıyla, aynı miktardaki film oluşturma çözeltisinin petrilere dökülmesiyle elde edilmiştir. Ancak, DL ilavesi filmlerin kalınlığında artışa neden olmuş ve ikinci bir katmanın sonradan oluşturulması nedeniyle en yüksek kalınlık değerleri iki katmanlı filmlerde gözlenmiştir $(p<0,05)$. Bunun yanı sıra, filmlere $\mathrm{N}$ ilave edilmesi filmlerin kalınlıkları üzerine etkili olmamıștır. Bunun sebebi, $\mathrm{CH}$ matrisi ile $\mathrm{N}$ arasındaki güçlü etkileşim olabilir [38]. Benzer şekilde, Haghighi ve ark. [3] CH ve jelatin bazlı iki katmanlı filmlerin kalınlıklarında artış gözlemlerken, etil laurol arjinat ilave edilmesinin kalınlık üzerine etkili olmadığını belirtmişlerdir.

Gıda ürünlerinin ışığın zararlı etkilerinden korunabilmesi ve tüketici kabul edilebilirliğinin arttırılması açısından kullanılan ambalaj materyalinin ışık geçirgenlik özellikleri önemlidir. Özellikle UV ışık ile artış gösteren oksidasyonun azaltılması için UVbloke edici filmler önem kazanmaktadır [39]. $\mathrm{CH}$ ve CHN film örnekleri en yüksek $\mathrm{T}$ (\%) değerleri gösterirken, filmlere DL ilavesi ve ikinci katman uygulaması ışık geçirgenlik değerlerinin azalmasına neden olmuştur $(\mathrm{p}<0,05)$. En yüksek ışık geçirgenliği değerleri $\mathrm{CHN}$ film örneğinde belirlenmiştir. $\mathrm{Bu}$ durum $\mathrm{N}$ ile $\mathrm{CH}$ arasındaki etkileşimin iyi olduğunu ve ara yüz fazında daha az ışık serpinmesi/yansıması yaşandığını göstermektedir [40]. Benzer şekilde en yüksek opaklık, CHN-DL ve CHN-DL/PCL film örneklerinde gözlenmiştir. $\mathrm{Bu}$ durum, bir fenolik bileşen olan DL'nin daha fazla ışık absorbe edebilir özellikte olmasından kaynaklanabilir [41]. İki katmanlı filmlerde gözlenen opaklık artışının bir diğer nedeni de ara yüzde oluşan boşluklar olabilir [37]. Sonuç olarak, CH filmlere DL ilave edilmesi, DL'nin $\mathrm{CH}$ matrisi ile daha az etkileşime girerek $\mathrm{CH}$ filmlerin daha kalın olmasına ve dolayısıyla opaklık değerleri daha yüksek ve işık geçirgenlik değerleri daha düşük filmler oluşmasına neden olmuş olabilir.

Tablo 3. Film örneklerinin renk değerleri

\begin{tabular}{llll} 
Film & $\boldsymbol{L}^{*}$ & $\boldsymbol{a}^{*}$ & $\boldsymbol{b}^{*}$ \\
\hline CH & $94,7 \pm 0,2^{\mathrm{a}}$ & $-1,2 \pm 0,5^{\mathrm{a}}$ & $5,8 \pm 0,1^{\mathrm{b}}$ \\
\hline CHN & $94,4 \pm 0,5^{\mathrm{a}}$ & $-0,2 \pm 0,1^{\mathrm{a}}$ & $6,5 \pm 0,5^{\mathrm{b}}$ \\
\hline CHN-DL & $94,7 \pm 0,2^{\mathrm{a}}$ & $-0,5 \pm 0,1^{\mathrm{a}}$ & $7,4 \pm 0,6^{\mathrm{ab}}$ \\
\hline CHN/PCL & $94,6 \pm 0,2^{\mathrm{a}}$ & $-0,2 \pm 0,1^{\mathrm{a}}$ & $5,8 \pm 0,1^{\mathrm{b}}$ \\
\hline CHN-DL/PCL & $94,3 \pm 0,3^{\mathrm{a}}$ & $-0,7 \pm 0,1^{\mathrm{a}}$ & $8,8 \pm 0,5^{\mathrm{a}}$
\end{tabular}

a-b Aynı sütundaki farklı harfler, örnekler arasında önemli farklılıkları gösterir $(\mathrm{p}<0,05)$ 
Film örneklerinin parlaklık ve $a^{*}$ değerleri arasında önemli farklılıklar gözlenmezken, DL ilavesinin $b^{*}$ değerlerinde artışa neden olduğu belirlenmiștir $(\mathrm{p}<0,05)$. Benzer şekilde Nilsuwan ve ark. [12] epigallokateşin ilave edilen polilaktik asit ve jelatin bazlı iki katmanlı filmlerin parlaklık değerlerinin önemli ölçüde değişmediğini, $a^{*}$ ve $b^{*}$ değerlerinin arttığını belirtmişlerdir.

\subsection{Film örneklerin antioksidan aktiviteleri}

Film örneklerine ait DPPH radikal süpürücü aktivite değerleri Şekil 2'de gösterilmiştir.

$\mathrm{CH}$ filmlere DL ilave edilmesi $\mathrm{CH}$ filmlerin antioksidan aktivitesini geliştirmiş ve en yüksek antioksidan aktivite değerleri CHN-DL/PCL iki katmanlı filmlerde gözlenmiştir $(p<0,05)$. CH, CHN ve CHN/PCL filmleri fenolik bileşen içermemesine rağmen \%3,21-3,98 aralığında antioksidan aktivite göstermiştir. Bu filmlerde gözlenen antioksidan aktivite, CH'da bulunan serbest $\mathrm{NH}_{2}$ - grupları ile serbest radikallerin stabil makromolekül radikaller oluşturmak için reaksiyona girmesi ile açıklanabilir [42]. DL içeren iki katmanlı filmlerin, PCL katmanının DL salımını azaltarak daha düşük antioksidan aktivite değerleri göstermesi beklenirken, en yüksek antioksidan aktivite değerini göstermiștir. Bu durum, ikinci katmanın çözücü şeklinde uygulanması ve bu nedenle çözücünün $\mathrm{CH}$ matrisine taşınmasıyla katmanlar arasındaki yapıya zarar vermesi sonucu DL'nin daha hızlı salım göstermesi ile açıklanabilir [11].

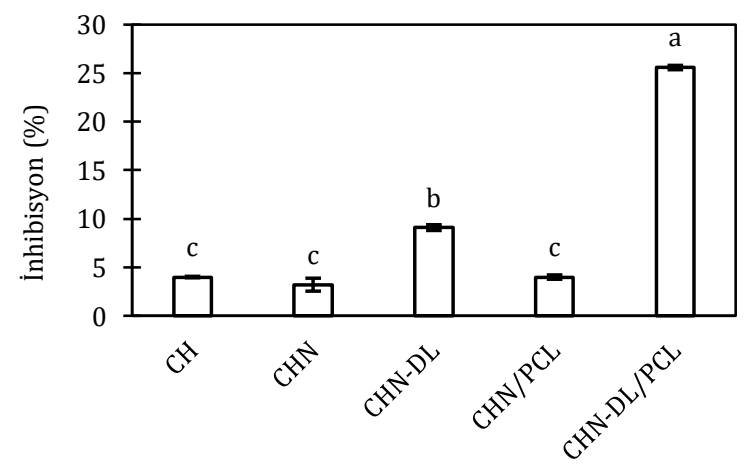

Şekil 2. Film örneklerine ait DPPH radikal süpürücü aktivite değerleri

a-c Farklı harfler, örnekler arasında önemli farklılıkları gösterir $(p<0,05)$

\subsection{Film örneklerinin antimikrobiyal aktiviteleri}

Seçilen bakterilere karşı film örneklerinin gösterdiği antimikrobiyal aktivite değerleri inhibisyon zonları (cm) şeklinde Tablo 4'te verilmiştir.

Filmlerin antimikrobiyal etkileri disk difüzyon yöntemi kullanılarak belirlenmiştir. $\mathrm{CH}$ doğal antimikrobiyal polimerlerden olmasına rağmen DL içermeyen film örnekleri test edilen mikroorganizmalara karşı inhibe edici etki göstermemiştir. Bu durum, inhibe edici etki gösteren $\mathrm{CH}$ bileşenlerinin katı besiyeri ortamında difüze olamaması ve ortama salım kabiliyetlerinin olmamasından kaynaklanmaktadır [6]. $\mathrm{CH}$ filmlere DL ilave edilmesi ile, E. coli'ye karşı CHN-DL/PCL hariç, test edilen tüm mikroorganizma gelişimleri etkin bir şekilde inhibe edilmiştir. D-limonenin antimikrobiyal etkisi, mikroorganizmanın hücre bütünlüğü ve duvar yapısını zarara uğratması, iletkenlikteki artışa bağlı olarak membran geçirgenliğini değiştirmesi ve hücre içi biyomakromoleküllerin hücre dıșına sızması şeklinde kendini göstermektedir [43]. İki katmanlı filmlere ait zon çapları ile tek katmanlı filmlere ait inhibisyon değerleri arasında istatistiksel olarak fark bulunamamıștır. Benzer şekilde, Haghighi ve ark. [3] etil laurol arjinat içeren $\mathrm{CH}$ ve jelatin bazlı iki katmanlı filmler ile tek katmanl filmlerin antimikrobiyal aktiviteleri arasında önemli farklılıklar gözlemlememişlerdir.

\section{Sonuç}

$\mathrm{Bu}$ çalışmada $\mathrm{CH}$ ve PCL bazlı iki katmanlı filmler geliştirilmiş ve bu filmlerin bazı fiziksel özellikleri tek katmanlı filmler ile karşılaștırılmıștır. Ayrıca, antioksidan ve antimikrobiyal aktivitelerini değerlendirmek için bu filmlere $\mathrm{N}$ ve DL eklenmiştir. İki katmanlı filmler su buharına karşı etkili bir bariyer özellik göstermiştir ve filmlerin opaklık değerlerinde artışa neden olurken ışık geçirgenliği değerlerinde azalmaya neden olduğu gözlenmiştir. DL'nin filmlere ilave edilmesi filmlerin kalınlığını ve su buharı geçirgenliğini etkilememiş, ancak filmlerin ışık geçirgenliğini, opaklık değerlerini ve $b^{*}$ değerlerini önemli ölçüde etkilemiştir. DL ile zenginleștirilmiş aktif filmler, antioksidan aktivite ve seçilen bakterilere karşı ve antimikrobiyal aktivite göstermiştir. Elde edilen sonuçlar, $\mathrm{N}$ ve DL ile zenginleştirilmiş $\mathrm{CH}$ ve PCL bazlı iki katmanlı filmlerin, gıda güvenliğini sağlamak ve gıdaların raf ömrünü uzatmak için ek bir biyoaktif fonksiyona sahip yenilenebilir ambalajların geliştirilmesinde potansiyele sahip olduğunu göstermektedir. Ancak, iki katmanlı filmlerin gerçek gıda uygulamalarında aktivitelerinin değerlendirilerek endüstriyel ölçekte optimum uygulamalarını araştırmak için daha fazla çalışmaya ihtiyaç vardır. Bu çalışma ile hazırlanan iki katmanlı filmler; DL içeren CH katmanının gıda ile temas halinde olup içerdiği NC ile kontrollü bir şekilde ortamda aktif özellikler sağlayan iç katman ve ikinci katman olan PCL'in hem su buharı bariyeri hem de ışık bariyeri sağlayan dış katman şeklinde kullanıldığı çok katmanlı biyobozunur gıda ambalaj malzemesi olma potansiyeline sahiptir. 
Tablo 4. Zon (cm) inhibisyon değerleri*

\begin{tabular}{lllll}
\hline Film & E. coli & L. monocytogenes & S. aureus & P. aeruginosa \\
\hline CH & - & - & - & - \\
\hline CHN & - & - & - & - \\
\hline CHN-DL & $2,1 \pm 0,1$ & $2,0 \pm 0,4$ & $1,7 \pm 0,1$ & $1,9 \pm 0,1$ \\
\hline CHN/PCL & - & - & - & - \\
\hline CHN-DL/PCL & - & $1,9 \pm 0,3$ & $1,8 \pm 0,2$ & $1,7 \pm 0,1$ \\
\hline
\end{tabular}

* Film çevresinde inhibisyon zonuna (film etrafındaki berrak alan) sahip film numuneleri arasında istatistiksel olarak önemli farklılık bulunmamıştır $(\mathrm{p}>0,05)$.

\section{Etik Beyanı}

Bu çalışmada, "Yükseköğretim Kurumları Bilimsel Araștırma ve Yayın Etiği Yönergesi" kapsamında uyulması gerekli tüm kurallara uyulduğunu, bahsi geçen yönergenin "Bilimsel Araştırma ve Yayın Etiğine Aykırı Eylemler" başlı̆̆ı altında belirtilen eylemlerden hiçbirinin gerçekleștirilmediğini taahhüt ederiz.

\section{Kaynakça}

[1] Abdelhedi, O., Nasri, R., Jridi, M., Kchaou, H., Nasreddine, B., Karbowiak, T., Debeaufort, F., Nasri, M. 2018. Composite bioactive films based on smooth-hound viscera proteins and gelatin: Physicochemical characterization and antioxidant properties. Food Hydrocolloids, 74, 176-186.

[2] Jridi, M., Abdelhedi, O., Zouari, N., Fakhfakh, N., Nasri, M. 2019. Development and characterization of grey triggerfish gelatin/agar bilayer and blend films containing vine leaves bioactive compounds. Food Hydrocolloids, 89, 370-378.

[3] Haghighi, H., De Leo, R., Bedin, E., Pfeifer, F., Siesler, H. W., Pulvirenti, A. 2019. Comparative analysis of blend and bilayer films based on chitosan and gelatin enriched with LAE (lauroyl arginate ethyl) with antimicrobial activity for food packaging applications. Food Packaging and Shelf Life, 19, 31-39.

[4] Cardoso, G. P., Dutra, M. P., Fontes, P. R., Ramos, A. de L.S., de Miranda Gomide, L. A., Ramos, E. M. 2016. Selection of a chitosan gelatin-based edible coating for color preservation of beef in retail display. Meat Science, 114, 85-94.

[5] Qiao, C., Ma, X., Zhang, J., Yao, J. 2017. Molecular interactions in gelatin/chitosan composite films. Food Chemistry, 235, 45-50.

[6] Leceta, I., Guerrero, P., De La Caba, K. 2013. Functional properties of chitosan-based films, In Carbohydrate Polymers, 1(1), 339-346.

[7] Elsabee, M. Z., Abdou, E. S. 2013. Chitosan based edible films and coatings: A review. Materials Science and Engineering C, 33(4), 1819-1841.
[8] Bellich, B., D'Agostino, I., Semeraro, S., Gamini, A., Cesàro, A. 2016. "The good, the bad and the ugly" of chitosans. Marine Drugs, 14(5), 99.

[9] Ahmed, J., Mulla M., Arfat, Y. A. 2017. Mechanical, thermal, structural and barrier properties of crab shell chitosan/graphene oxide composite films. Food Hydrocolloids, 71, 141-148.

[10] Valencia-Sullca, C., Vargas, M., Atarés, L., Chiralt, A. 2018. Thermoplastic cassava starchchitosan bilayer films containing essential oils. Food Hydrocolloids, 75, 107-115.

[11] Söğüt, E., Seydim, A.C. 2018. Characterization of cyclic olefin copolymer-coated chitosan bilayer films containing nanocellulose and grape seed extract. Packaging Technology and Science, 31(7), 499-508.

[12] Nilsuwan, K., Guerrero, P., de la Caba, K., Benjakul, S., Prodpran, T. 2020. Properties and application of bilayer films based on poly (lactic acid) and fish gelatin containing epigallocatechin gallate fabricated by thermo-compression molding. Food Hydrocolloids, 105, 105792.

[13] Khan, A., Khan, R. A., Salmieri, S., Le Tien, C., Riedl ,B., Bouchard, J., Chauve, G., Tan, V., Kamal, M.R., Lacroix, M. 2012. Mechanical and barrier properties of nanocrystalline cellulose reinforced chitosan based nanocomposite films. Carbohydrate Polymers, 90(4), 1601-1608.

[14] Dehnad, D., Mirzaei, H., Emam-Djomeh, Z., Jafari, S. M., Dadashi, S. 2014. Thermal and antimicrobial properties of chitosannanocellulose films for extending shelf life of ground meat. Carbohydrate Polymers, 109, 148154.

[15] Khan, A., Huq, T., Khan, R. A., Riedl, B., Lacroix, M. 2014. Nanocellulose-Based Composites and Bioactive Agents for Food Packaging. Critical Reviews in Food Science and Nutrition, 54(2), 163-174.

[16] Andresen, M., Stenstad, P., Møretrø, T., Langsrud, S., Syverud, K., Johansson, L. S., Stenius, P. 2007. Nonleaching antimicrobial films prepared from surface-modified microfibrillated cellulose. Biomacromolecules, 8(7), 2149-2155.

[17] Choi, J. G., Kang, O. H., Lee, Y. S., Oh, Y. C., Chae, H. S., Jang, H. J., Shin, D. W., Kwon, D. Y., 
2009. Antibacterial activity of methyl gallate isolated from galla rhois or carvacrol combined with nalidixic acid against nalidixic acid resistant bacteria. Molecules, 14(5), 1773-1780.

[18] Galus, S., Kadzińska, J. 2015. Food applications of emulsion-based edible films and coatings. Trends in Food Science \& Technology, 45(2), 273-283.

[19] Ramos, M., Valdes, A., Beltran, A., Garrigós, M. C. 2016. Gelatin-based films and coatings for food packaging applications. Coatings, 6(4), 41.

[20] Rivero, S., García M. A., Pinotti, A. 2009. Composite and bi-layer films based on gelatin and chitosan. Journal of Food Engineering, 90(4), 531-539.

[21] Sogut, E., Seydim, A. C. 2019. The effects of chitosan-and polycaprolactone-based bilayer films incorporated with grape seed extract and nanocellulose on the quality of chicken breast fillets. LWT, 101, 799-805.

[22] Pereda, M., Ponce A. G., Marcovich N. E., Ruseckaite R. A., Martucci, J. F. 2011. Chitosangelatin composites and bi-layer films with potential antimicrobial activity. Food Hydrocolloids, 25(5), 1372-1381.

[23] Sharmin, N., Khan, R. A., Salmieri, S., Dussault, D., Lacroix, M. 2012. Fabrication and Characterization of Biodegradable Composite Films Made of Using Poly(caprolactone) Reinforced with Chitosan. Journal of Polymers and the Environment, 20(3), 698-705.

[24] Joseph, C. S., Prashanth, K. V. H., Rastogi, N. K., Indiramma, A. R., Reddy, S. Y., Raghavarao, K. S. M. S. 2011. Optimum Blend of Chitosan and Poly( $\varepsilon$-caprolactone) for Fabrication of Films for Food Packaging Applications. Food and Bioprocess Technology, 4(7), 1179-1185.

[25] Alix, S., Mahieu, A., Terrie, C., Soulestin, J., Gerault, E., Feuilloley, M. G. J., Gattin, R., Edon, V., Ait-Younes, T., Leblanc, N. 2013. Active pseudomultilayered films from polycaprolactone and starch based matrix for food-packaging applications. European Polymer Journal, 49(6), 1234-1242.

[26] Gaikwad, K. K., Lee, S. M., Lee, J. S., Lee, Y. S. 2017. Development of antimicrobial polyolefin films containing lauroyl arginate and their use in the packaging of strawberries. Journal of Food Measurement and Characterization, 11(4), 17061716.

[27] Zhu, J.-Y., Tang, C.-H., Yin, S.-W., Yang, X.-Q. 2018. Development and characterization of novel antimicrobial bilayer films based on Polylactic acid (PLA)/Pickering emulsions. Carbohydrate Polymers, 181, 727-735.
[28] Xing, C., Qin, C., Li, X., Zhang, F., Linhardt, R. J., Sun, P., Zhang, A. 2019. Chemical composition and biological activities of essential oil isolated by HS-SPME and UAHD from fruits of bergamot. LWT, 104, 38-44.

[29] Settanni, L., Palazzolo, E., Guarrasi, V., Aleo, A., Mammina, C., Moschetti, G., Germanà, M. A. 2012. Inhibition of foodborne pathogen bacteria by essential oils extracted from citrus fruits cultivated in Sicily. Food Control, 26(2), 326-330.

[30] Froiio, F., Ginot, L., Paolino, D., Lebaz, N., Bentaher, A., Fessi, H., Elaissari, A. 2019. Essential oils-loaded polymer particles: Preparation, characterization and antimicrobial property. Polymers, 11(6), 1017.

[31] Li, P.-H., Chiang, B.-H. 2012. Process optimization and stability of D-limonene-inwater nanoemulsions prepared by ultrasonic emulsification using response surface methodology. Ultrasonics Sonochemistry, 19(1), 192-197.

[32] Anonim, 2016. ASTM, 95AD, Standard Test Methods for Water Vapor Transmission of Materials. Annual Book of ASTM, 552, 12.

[33] Friesen, K., Chang, C., Nickerson, M. 2015. Incorporation of phenolic compounds, rutin and epicatechin, into soy protein isolate films: Mechanical, barrier and cross-linking properties. Food Chemistry, 172, 18-23.

[34] Sánchez-Moreno, C., Larrauri, J. A., SauraCalixto, F. 1998. A procedure to measure the antiradical efficiency of polyphenols. Journal of the Science of Food and Agriculture, 76(2), 270276.

[35] Cao, N., Yang, X., Fu, Y. 2009. Effects of various plasticizers on mechanical and water vapor barrier properties of gelatin films. Food Hydrocolloids, 23(3), 729-735.

[36] McHugh, T.H., Avena-Bustillos, R., Krochta, J. M. 1993. Hydrophilic edible films: modified procedure for water vapor permeability and explanation of thickness effects. Journal of Food Science, 58(4), 899-903.

[37] Salgado, P. R., D’Amico, D. A., Seoane, I. T., Iglesias Montes, M., Mauri, A. N., Cyras, V. P. 2021. Improvement of water barrier properties of soybean protein isolate films by poly (3hydroxybutyrate) thin coating. Journal of Applied Polymer Science, 138(5), 49758.

[38] Sogut, E., Cakmak, H. 2020. Utilization of carrot (daucus carota l.) Fiber as a filler for chitosan based films. Food Hydrocolloids, 106, 105861.

[39] Wu, J., Sun, X., Guo, X., Ge, S., Zhang, Q. 2017. Physicochemical properties, antimicrobial 
activity and oil release of fish gelatin films incorporated with cinnamon essential oil. Aquaculture and Fisheries, 2(4), 185-192.

[40] Ahmed, S., Ikram, S. 2016. Chitosan and gelatin based biodegradable packaging films with UV-light protection. Journal of Photochemistry and Photobiology B: Biology, 163, 115-124.

[41] Kanmani, P., Rhim, J.-W. 2014. Antimicrobial and physical-mechanical properties of agarbased films incorporated with grapefruit seed extract. Carbohydrate Polymers, 102, 708-716.

[42] Yen, M.-T., Yang, J.-H., Mau, J.-L. 2008. Antioxidant properties of chitosan from crab shells. Carbohydrate Polymers, 74(4), 840-844.

[43] Han, Y., Sun, Z., Chen, W. 2020. Antimicrobial susceptibility and antibacterial mechanism of limonene against Listeria monocytogenes. Molecules, 25(1), 33. 